\title{
Pemetaan konsep fisika siswa kelas XI pada kurikulum 2013
}

\author{
M Musdar ${ }^{1}$ \\ ${ }^{1}$ Prodi Pendidikan Fisika, Universitas Serambi Mekkah, Kota Banda Aceh 23245, Indonesia \\ E-mail: musdar_fisika@yahoo.com
}

Received: 1412 2017. Revision: 1912 2017. Accepted: 02032018

\begin{abstract}
Abstrak
Penelitian ini dilakukan untuk mengetahui pemetaan penguasaan konsep fisika siswa kelas XI IA 1 dan XI IA2 pada kurikulum 2013 di SMA N 4 Banda Aceh penelitian ini melibatkan 67 sampel dengan menggunakan pendekatan kuantitatif serta instrument penelitian berupa soal ujian fisika kelas XI semester ganjil 2017-2018 dengan menghitung persentase, untuk penguasaan konsep untuk materi, Elastisitas Bahan, Kesetimbangan benda tegar, Fluida Statis dan Fluida Dinamis serta Suhu Kalor, setelah dianalisis berdasarkan hasil ujian maka untuk materi Elastisitas Bahan dikuasai oleh siswa sebanyak 44, 6\% sedangkan untuk materi fluida statis dan fluida dinamis dikuasai oleh siswa sebanyak $45,01 \%$ sedangkan untuk materi kesetimbangan benda tegar dikuasai oleh siswa sebanyak $41,78 \%$ dan yang terakhir untuk materi suhu dan kalor dikuasai oleh siswa sebanyak 39,5\%, untuk penguasaan konsep yang paling banyak dikuasai untuk konsep fluida statis dan fluida dinamis serta yang paling sedikit dikuasai materi suhu dan kalor
\end{abstract}

Kata Kunci: pemetaan; penguasan konsep; kurikulum 2013; konsep fisika

\section{Mapping the concept of physics students of class XI in the curriculum 2013}

\begin{abstract}
This research aim to know the mastery mapping of physics concept of students class XI IA 1 and class XI IA 2 curriculum 2013 in SMAN 4 Banda Aceh this reasearch use quantitative approach and involove 667 sample. The instrument of this reaseearch is the test sheet of elastisity concept, equillibrium of strong body concept, fluid static and dinamic and temperature concept. The data of this research analyzed with percentage formula and the result are $44.6 \%$ student mastery the elastisity concept $45.01 \%$ student mastery the fluid static and dinamic concept $41.78 \%$, student master the equilibrium of strong body concept and $39.5 \%$ student master the temperature concept. Based of the result of this reasearch the conclusion is the student can master the fluid static and dinamic concept easier then other concept.
\end{abstract}

Keywords: mapping; mastering concept; curriculum 2013, physics concept

\section{PENDAHULUAN}

Rendahnya mutu pendidikan Indonesia harus segera dibenahi, dimulai dari penyempurnaan kurikulum terdahulu sehingga muncul kurikulum 2013. Pelakasanaan kurikulum 2013 dilandasi sebuah kepentingan untuk mempersiapkan generasi muda dalam kompetensi sikap, keterampilan dan pengetahuan (Kustijono \& HM, 2014). Kurikulum 2013 yang mulai diberlakukan oleh pemerintah menyempurnakan kurikulum 2006 memberikan perubahan yang cukup mendasar terutama pada standar proses pembelajaran (Wiyono, 2015).

Guru sebagai orang yang mengelola proses pembelajaran tentunya harus mampu meningkatkan kemampuan dalam membuat perencanaan pembelajaran, pelaksanaan, dan penilaian hasil belajar peserta didik dengan baik dan disesuaikan dengan kemampuan peserta didik, sekaligus guru harus memiliki kompetensi pedagogik, sosial, ilmu pengetahuan dan psikologi dalam mendidik peserta didiknya (Rohmauddin 2014). Pengaruh rendahnya kualitas belajar siswa juga bergantung pada komponen-komponen 


\section{Jurnal Pendidikan Fisika dan Keilmuan (JPFK), 4 (1), 2018 - 37}

M. Musdar

antara lain siswa, kurikulum, guru, metode, sarana-prasarana dan lingkungan. Proses belajar-mengajar dapat berjalan efektif bila seluruh komponen yang berpengaruh saling mendukung dalam rangka mencapai tujuan. Misalnya ketertarikan siswa, motivasi siswa, metode guru bervariasi, teknik guru dalam mengajar dikelas mempengaruhi proses dan hasil belajar siswa. Apabila metode yang digunakan dalam penyampaian materi-materi tertentu sesuai, maka siswa akan termotivasi dalam proses belajar. Kegiatan proses belajar mengajar juga perlu didukung oleh desain pembelajaran yang menyenangkan hal ini bisa juga mempengaruhi hasil belajar, banyak komponen yang mempengaruhi hasil belajar seperti sarana dan prasarana penunjang dan lainnya (Pribadi, 2013). Penguasaan konsep memberikan pengertian bahwa konsep konsep yang diajarkan kepada siswa bukanlah sekedar bahan hapalan saja, tetapi konsep itu harus dipahami agar dapat digunakan untuk dapat memecahkan masalah yang dihadapi. Penguasaan konsep merupakan tingkatan hasil proses belajar seseorang sehingga dapat mendefenisikan atau menjelaskan suatu bagian informasi dengan kata-kata sendiri, dengan kemampuan siswa menjelaskan atau mendefenisikan berarti siswa tersebut telah memahami konsep atau prinsip dari bahanbahan pelajaran, meskipun penjelasanyang diberikan susunan kalimatnya tidak sama dengan konsep yang diberikan, tetapi maknanya tidak berbeda. (Dahar, 2011). Penguasaan konsep Fisika oleh siswa akan lebih berhasil jika diterapkan model pembelajaran sesuai yang dapat membuat siswa mencari, menyelesaikan masalah dan memahami Fisika itu sendiri sehingga siswa dapat membangun konsep konsep Fisika atas dasar nalarnya sendiri yang kemudian dikembangkan atau mungkin diperbaiki oleh guru yang mengajar. Sungkawan, (2013)

Menurut Hidayat (2013) Struktur organisasi kurikulum merupakan pola dan susunan mata pelajaran yang harus ditempuh oleh peserta didik dalam proses pembelajaran.Menurut Sukadimanta (2013) Di antara prinsip-prinsip pada kurikulum 2013 yaitu pembelajaran yang memotivasi siswa menjadi peserta didik yang aktif, jika biasanya kegiatan pembelajaran dimulai dengan penyampaian informasi dari guru sebagai sumber informasi, maka pada kurikulum 2013 kegiatan inti dimulai dengan siswa mengamati fenomena atau fakta tertentu sehingga guru dapat membangkitkan rasa ingin tahu siswa terhadap fenomena atau fakta tersebut dengan bertanya.

Salah satu kegiatan evaluasi dalam pendidikan adalah evaluasi pembelajaran. Kegiatan ini dilakukan seorang guru paling tidak untuk mengetahui bagaimanakah (1) keberhasilan pembelajaran yang telah dilakukan; (2) kemampuan dan daya serap peserta didik terhadap materi yang telah dibelajarkan; dan (3) informasi yang sangat berharga sebagai balikan (feedback) bagi guru dalam memperbaiki kegiatan pembelajaran yang telah dilakukan seperti diungkapkan oleh Yulianto (2008). Selain memotivasi siswa menjadi peserta didik yang aktif, pada kurikulum 2013 menggunakan pendekatan ilmiah atau yang sering disebut pendekatan saintifik. Hal ini dikemukakan oleh Hosnan (2014:34) bahwa implementasi kurikulum 2013 dalam pembelajaran dengan menggunakan pendekatan saintifik merupakan proses pembelajaran yang dirancang agar peserta didik secara aktif mengonstruk konsep, hukum atau prinsip melalui tahapan-tahapan mengamati, merumuskan masalah, merumuskan hipotesis, mengumpulkan data dengan berbagai teknik, menganalisis data, menarik kesimpulan dan mengkomunikasikan konsep, hukum, atau prinsip yang ditemukan. Kesulitan yang dirasakan oleh siswa bergantung pada pemahaman materi yang diajarkan oleh guru. Guru harus mampu menyesuaikan kesulitan siswa dengan pemahaman materi yang diajarkan. Dan merupakan satu hal yang penting untuk suksesnya hasil belajar siswa. Untuk itu, guru dituntut harus mampu mencoba model-model pembelajaran baru yang mampu memberikan variasi dalam pelaksanaan pembelajaran dikelas, sehingga akan menarik siswa untuk dapat menangkap materi yang disampaikan. Dengan adanya kurikulum 2013 diharapkan guru tidak hanya menggunakan buku pelajaran sebagai satu-satunya sumber belajar siswa, namun dapat menggunakan berbagai media lain seperti lingkungan dan alat peraga yang berupa gambar, diagram, tabel, dan lain-lain. Dengan menggunakan scientific approach diharapkan peserta didik dapat memperoleh pengetahuan secara ilmiah, tidak hanya bersumber dari apa yang 
disampaikan guru, tetapi mereka melihat, mengamati dan merumuskan sendiri berdasarkan fakta dan fenomena yang diperoleh pada saat proses belajar-mengajar. Selain membuat peserta didik menjadi aktif, scientific aproach dapat mengembangkan kemampuan berpikir peserta didik. Berdasarkan hasil wawancara dengan guru Fisika di SMA Negeri 4 Banda Aceh pada tanggal 2 November 2017 menyatakan bahwa prestasi belajar siswa pada mata pelajaran fisika sangat rendah berdasarkan ketercapaian KKM dengan nilai 70 tidak semua tercapai untuk nilai tersebut umunya berdasarkan hasil ujian siswa rata rata 63,5 terutama yang berkaitan dengan perhitungan dan pemakaian rumus fisika..

\section{METODE}

Tempat Penelitian dilakukan di Sekolah Menengah Atas Negeri 4 Banda Aceh yang beralamat di jalan Panglima. Nyak Makam kecamatan Kuta Alam, sedangkan waktu penelitian dilakukan pada tanggal 2 s/d 9 Desember 2017 untuk pengambilan data membutuhkan waktu satu hari setelah ujian semester selesai Adapun sampel dalam penelitian ini adalah siswa kelas XI IA 1 dan XI IA 2. Teknik pengambilan sampel dalam penelitian ini adalah dengan cara purposing sampling. Sugiyono (2012:124), "purposing sampling adalah teknik penentuan sampel dengan pertimbangan tertentu". Teknik ini dipilih karena peneliti harus memperhatikan jumlah siswa yang tidak boleh terlalu banyak karena yang diamati adalah partisipasi siswa dalam pembelajaran.
Untuk penelitian ini rincian data yang diperlukan berupa soal hasil ujian akhir fisika semester ganjil tahun ajaran 2017-2018 Berdasarkan permasalahan yang akan diteliti oleh penulis, maka penelitian ini menggunakan pendekatan secara kuantitatif. Tujuannya adalah mendeskripsikan fenomena-fenomena dari hasil temuan lapangan sesuai fokus permasalahan yang diteliti berdasarkan fakta lapangan. Pengumpulan data dilakukan dengan cara menganalisis butir soal ujian semester Ganjil 2017-2018, soal ujian berbentuk pilihan ganda yang berjumlah 35 butir dengan 5 item pilihan, pada semester ganjil 2017-2018 materi yang diajarkan ada 4 materi yaitu, kesetimbangan benda tegar, Elastisitas bahan, Fluida Statis dan Fluida Dinamis serta Suhu Kalor. Adapun teknik analisis data dengan menggunakan persentase dari keempat komponen soal yang berhubungan dengan empat komponen soal tersebut.

\section{HASIL DAN PEMBAHASAN}

Berdasarkan Hasil penelitian yang telah dianalisis yang terdiri dari terdiri dari 67 sampel kelas XI IA1 dan XI IA2. Berdasarkan grafik dan tabel tersebut hasilnya terlihat, sedangkan untuk penguasan keempat materi bisa di lihat di diagram lingkaran, untuk komposisi soal ujian 9\% untuk materi elastisitas bahan, 37\% untuk materi fluida statis dan fluida dinamis, sedangkan untuk materi kesetimbangan benda tegar komposisi soal ada $17 \%$ dan untuk materi suhu kalor terdapat.

Tabel 1. Hasil Jawaban siswa berdasarkan butir soal

\begin{tabular}{llll}
\hline $\begin{array}{c}\text { No } \\
\text { Soal }\end{array}$ & \multicolumn{1}{c}{ Materi Soal } & $\begin{array}{c}\text { Persentase } \\
\text { jawaban }\end{array}$ & \multicolumn{1}{c}{ Kategori } \\
\hline 1 & Elastisitas Bahan & $61.2 \%$ & Mudah \\
\hline 2 & Elastisitas Bahan & $4.5 \%$ & Sangat Sukar \\
\hline 3 & Elastisitas Bahan & $68.7 \%$ & Mudah \\
\hline 4 & Fluida Statis dan dinamis & $58.2 \%$ & Sedang \\
\hline 5 & Fluida Statis dan dinamis & $83.9 \%$ & Sangat Mudah \\
\hline 6 & Fluida Statis dan dinamis & $53.7 \%$ & Sedang \\
\hline 7 & Fluida Statis dan dinamis & $16.4 \%$ & Sangat Sukar \\
\hline 8 & Suhu Kalor & $83.6 \%$ & Sangat Mudah \\
\hline 9 & Suhu Kalor & $20.9 \%$ & Sukar \\
\hline 10 & Suhu Kalor & $4.5 \%$ & Paling Sukar \\
\hline 11 & Suhu Kalor & $38.8 \%$ & Sukar \\
\hline 12 & Suhu Kalor & $73.1 \%$ & Mudah \\
\hline & & & \\
\hline
\end{tabular}


Jurnal Pendidikan Fisika dan Keilmuan (JPFK), 4 (1), 2018 - 39

M. Musdar

\begin{tabular}{llll}
\hline 13 & Suhu Kalor & $14.9 \%$ & Sangat Sukar \\
\hline 14 & Suhu Kalor & $0 \%$ & Sangat Sukar \\
\hline 15 & Kesetimbangan Benda Tegar & $58.2 \%$ & Sedang \\
\hline 16 & Kesetimbangan Benda Tegar & $20.9 \%$ & Sukar \\
\hline 17 & Kesetimbangan Benda Tegar & $6 \%$ & Sangat Sukar \\
\hline 18 & Kesetimbangan Benda Tegar & $79.1 \%$ & Mudah \\
\hline 20 & Kesetimbangan Benda Tegar & $49.3 \%$ & Sedang \\
\hline 21 & Fluida Statis dan dinamis & $43.3 \%$ & Sedang \\
\hline 22 & Fluida Statis dan dinamis & $85.1 \%$ & Sangat Mudah \\
\hline 23 & Fluida Statis dan dinamis & $47.8 \%$ & Sedang \\
\hline 24 & Fluida Statis dan dinamis & $74.6 \%$ & Mudah \\
\hline 25 & Suhu Kalor & $88.9 \%$ & Sukar \\
\hline 26 & Suhu Kalor & $31.3 \%$ & Sangat Mudah \\
\hline 27 & Suhu Kalor & $25.4 \%$ & Sukar \\
\hline 28 & Suhu Kalor & $38.8 \%$ & Sukar \\
\hline 29 & Suhu Kalor & $28.4 \%$ & Sukar \\
\hline 30 & Suhu Kalor & $22.4 \%$ & Sukar \\
\hline 31 & Suhu Kalor & $65.7 \%$ & Mudah \\
\hline 32 & Kesetimbangan Benda Tegar & $11.9 \%$ & Sangat Sukar \\
\hline 33 & Kesetimbangan Benda Tegar & $25.4 \%$ & Sukar \\
\hline 34 & Fluida Statis dan dinamis & $4.5 \%$ & Sangat Sukar \\
\hline 35 & Fluida Statis dan dinamis & $74.6 \%$ & Mudah \\
\hline & & & \\
\hline
\end{tabular}

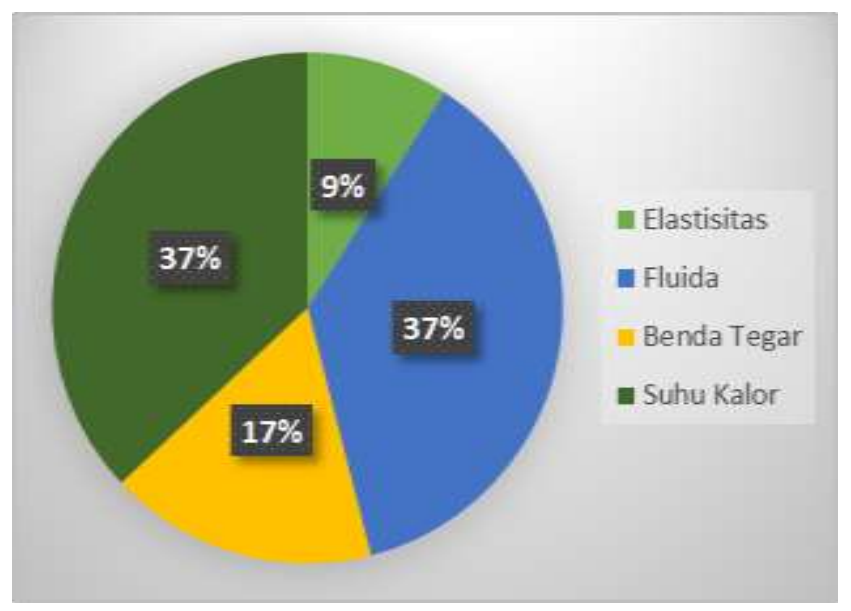

Gambar 2. Prosentase penggunaan materi ajar untuk soal ujian

Sedangkan untuk penguasan materi berdasarkan hasil ujian makan untuk materi Elastisitas Bahan dikuasai oleh siswa sebanyak 44, 6\% sedangkan untuk materi fluida statis dan fluida dinamis dikuasai oleh siswa sebanyak $45,01 \%$ sedangkan untuk materi kesetimbangan benda tegar dikuasai oleh siswa sebanyak $41,78 \%$ dan yang terakhir untuk materi suhu dan kalor dikuasai oleh siswa sebanyak $39,5 \%$ 


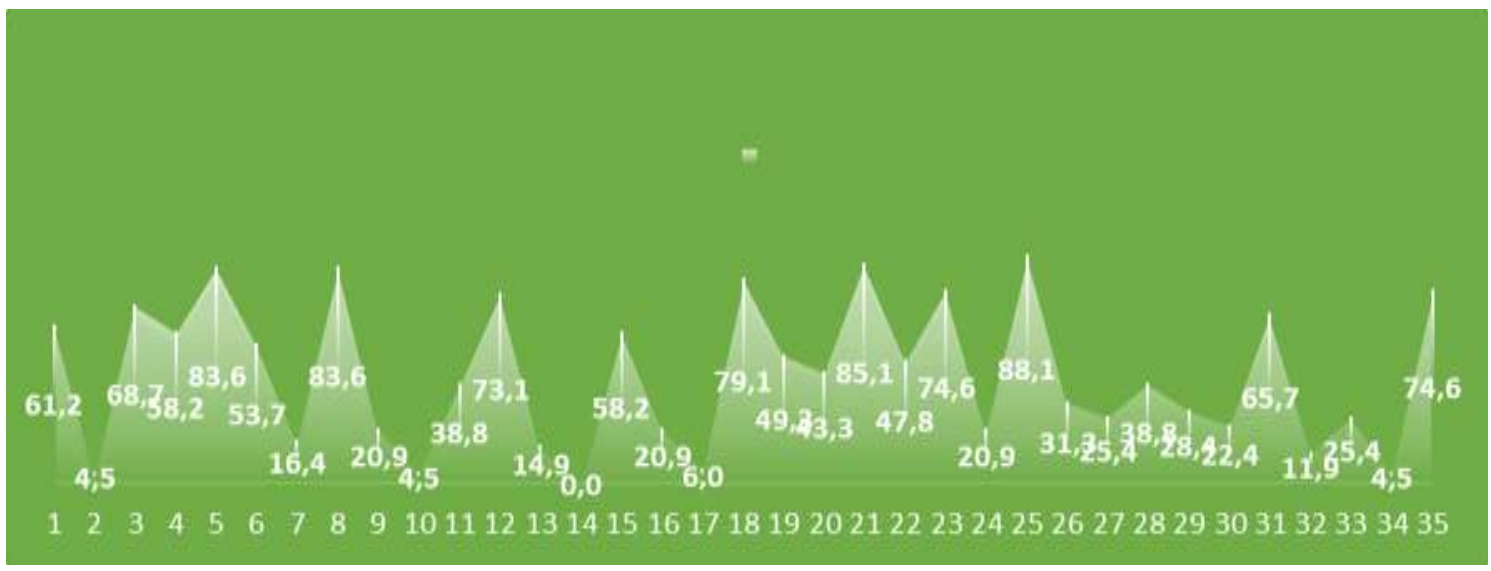

Gambar 2. Hasil Pemetaan Penguasaan Konsep Fisika

Berdasarkan uraian diatas bahwa penguasan konsep lebih banyak dikuasai untuk materi fluida statis dan fluida dinamis, dikarenakan fluida ini sangat nyata dalam kehidupan sehari hari hingga begitu ada permasalahan tentang fluida siswa langsung biasa menganalisis permasalahan tersebut, untuk materi yang paling kecil penguasaannya yaitu materi suhu dan kalor, hal ini dikarenakan pada materi suhu kalor ini selain memiliki persamaan matematika juga terdapat grafik grafik yang membutuhkan waktu yang lama untuk menganalisis grafik tersebut, banyak permasalahan ketika seorang siswa belajar fisika banyak konsep dan perhitungan dasar tidak siswa kuasai.

\section{SIMPULAN}

Berdasarkan hasil diatas maka dapat diambil kesimpulan bahwa penguasan konsep untuk materi ajar semester ganjil tahun ajaran 2017-2018 di SMA Negeri 4 Banda Aceh paling banyak dikuasai oleh siswa yaitu materi fluida statis dan fluida dinamis karena materi ini abstrak dan langsung bisa dilihat dalam dunia nyata, oleh sebab itu penulis menyarankan untuk penelitian selanjutnya meneliti hubungan pengetahuan siswa atau konsep dengan kemmpuan psikomotorik siswa.

\section{DAFTAR PUSTAKA}

Arikunto, S. (2010). Prosedur Penelitian Suatu Pendekatan Praktik. Jakarta: Rineka Cipta.

Dahar, R.W. (2011). Teori-Teori Belajar dan Pembelajaran. Bandung: Erlangga.
Hidayat, S. (2013). Pengembangan Kurikulum Baru, Bandung, Remaja Rosdakarya

Hosnan, H. (2014). Pendekatan Scientific dan konstektual dalam Pembelajaran abad $21 \quad$ kunci sukses implementasi kurikulum 2013. Bogor: Ghalia, Indonesia.

Kustijono, R., \& HM, E. W. (2014). Pandangan guru terhadap pelaksanaan kurikulum 2013 dalam pembelajaran fisika SMK di Kota Surabaya. Jurnal Penelitian Fisika dan Aplikasinya (JPFA), 4(1), 1-14.

Pribadi, B. A. (2011). Model Desain Sistem Pelajaran. Jakarta: Dian Rakyat.

Rusijono \& Yulianto, B. (2008). Asesmen Pembelajaran: Bahan Pelatihan Program Continue Education bagi Guru SD di Lingkungan Dinas Kota Surabaya tahun 2008. Surabaya: Dinas Pendidikan Kota Surbaya UNESA.

Reksoatmodjo, T.N. (2010). Pengembangan Kurikulum Pendidikan Teknologi dan Kejuruan. Bandung: Refika Aditama.

Rohmanudin, R. (2014). Pemahaman Guru tentang Kurikulum 2013 SMK dan Implementasinya pada SMK Program Keahlian Teknik Mesin (Studi Kasus pada SMK Negeri 1 Kertosono). Skripsi tidak diterbitkan. Malang: UM 
Setyosari, P. (2010). Metode Penelitian Pendidikan dan Pengembangan. Jakarta: Prenada Media Group.

Soedijarto, S. (2004). Kurikulum, Sistem Evaluasi, dan Tenaga Pendidikan sebagai Unsur Strategis dalam Penyelenggaraan Sistem pengajaran Nasional. Jurnal Pendidikan Penabur, 3 (3): 28-37

Sugiyono, S. (2012). Metode Penelitian Pendidikan. Bandung: Alfabeta.

Sukmadinata, N. S. (2013). Pengembangan Kurikulum, Teori dan Praktek. Bandung: PT. Remaja Rosdakarya.

Sungkawan, R. (2013). Analisis Penguasaan

Konsep Awal Fisika
Padapembelajaran Menggunakan Model Advance Organizer Berbasis Eksperimen Terhadap Hasil Belajar Fisika. Jurnal Pendidikan Fisika, 2(2), 73-80.

Wiyono, K. (2015). pengembangan Model pembelajaran Fisika berbasis ICT Pada Implementasi kurikulum 2013. Jurnal Inovasi Dan Pembelajaran Fisika, 2(2), 123-131. 